\title{
TANTANGAN DAN STRATEGI PELAYANAN ANAK DI ERA PASCAMODERN
}

\author{
Marhaenita Paripurna Zendrato*
}

\begin{abstract}
Children ministry nowadays faces challenges both from inside and outside church. This article focuses on the external challenges, namely the postmodern influence on the paradigm of the generation $Z$ and what the church can do to respond. Some challenges in as well as opportunities for the ministry of the generation $Z$ include the center on technology and media, the rising of new morality that set asides the value of an absolute truth, the emphasis on experience and not only on fact, and lastly, the rejection of authority or figures with authority and the appreciation for personality that is real, authentic, and trustworthy. In the face of these challenges, this article proposes several thoughts to be considered by the church for its children ministry in current context, namely: first, including children in the common worship, together with the adult congregations, as a means of nurturing the children's' faith. Secondly, in preaching, the children minister needs to exercise open approach Bible study, not close one, where children are led to ponder and discover from the biblical narratives truths and values for their personal lives. Lastly, to encourage and equip both parents to regain roles that God has designed for them, to actively participate in the spiritual formation of their children.
\end{abstract}

Keywords: children ministry, worldview, generation Z.

* Penulis adalah mahasiswa Pascasarjana STT Amanat Agung. Penulis dapat dihubungi melalui email: ev.marhaenita@gmail.com. 
Abstrak: Pelayanan anak dewasa ini mendapatkan tantangan baik dari dalam maupun dari luar gereja. Artikel ini secara khusus menyoroti tantangan dari luar, yaitu pengaruh pascamodernisme terhadap paradigma generasi $Z$ dan apa yang dapat gereja lakukan dalam meresponinya. Beberapa tantangan yang sekaligus dapat menjadi peluang bagi pelayanan kepada generasi Z adalah: adanya pemusatan pada teknologi dan media, munculnya moralitas baru yang menggeser nilai kebenaran absolut, penekanan pada pengalaman dan bukan hanya fakta, dan terakhir adalah penolakan pada otoritas atau figur otoritatif dan apresiasi pada pribadi yang real, otentik, dan dapat dipercaya. Berhadapan dengan tantangan demikian, beberapa hal yang perlu dipertimbangkan oleh gereja dalam melakukan pelayanan anak dalam konteks kekinian yang diusulkan dalam artikel ini antara lain: pertama, melibatkan anak-anak dalam ibadah bersama dengan jemaat dewasa sebagai salah satu bentuk pengasuhan iman anak. Kedua, dalam hal pemberitaan firman, pelayan anak perlu menerapkan sistem studi Alkitab yang terbuka bukan yang tertutup, di mana anak dituntun untuk memikirkan dan menemukan kebenaran serta nilai-nilai pribadi mereka sendiri dari kisah-kisah Alkitab. Terakhir, mendorong serta memperlengkapi orang tua, yaitu ayah dan ibu untuk kembali kepada peran yang Allah rancang bagi para orang tua untuk berperan aktif dalam pembentukan spiritual anakanaknya.

Kata-kata kunci: pelayanan anak, pandangan dunia (worldview), generasi Z.

\section{Pendahuluan}

Pelayanan anak dewasa ini mendapatkan tantangan baik dari dalam maupun dari luar gereja. ${ }^{1}$ Bagi sebagian orang, melayani anak-

1. Adapun yang penulis maksudkan dengan pelayanan anak dalam artikel ini adalah pelayanan kepada anak-anak yang dilakukan oleh gereja sebagai upaya 
anak dianggap kurang terlalu penting. Bahkan banyak gereja yang mengabaikan pelayanan anak dan hanya terfokus kepada pelayanan orang dewasa saja. ${ }^{2} \mathrm{Hal}$ ini tampak dalam jumlah tenaga pelayan anak yang masih minim dan kualitasnya yang tidak memenuhi standar. Beberapa gereja bahkan belum memiliki struktur pelayanan anak yang jelas, dan kalau pun sudah ada masih belum efektif dalam gerak operasionalnya. Namun demikian, tantangan dalam pelayanan anak bukan saja datang dari intern gereja-di mana pelayanan ini masih dianggap kurang terlalu penting, tantangan lain datang dari luar gereja.

Zaman telah berubah di mana pelayanan anak di gereja sedang berhadapan dengan anak-anak yang bertumbuh dalam budaya pascamodern, yang pola pikirnya mencerminkan prinsip-prinsip pascamodernisme. Anak-anak ini tidak melihat dunia dengan cara yang sama seperti orang dewasa melihatnya. Mereka tidak menghargai hal yang sama dengan yang dihargai oleh orang dewasa. Mereka juga tidak melihat konsep kebenaran dan realitas dengan cara yang sama seperti yang orang dewasa lakukan. Namun ini tidak berarti bahwa pandangan

untuk menolong anak bertumbuh dalam iman Kristen melalui kelas-kelas Sekolah Minggu yang diadakan di gereja. Pelayanan anak di gereja mencakup anak usia balita sampai remaja awal (12-15 tahun).

2. "Pelayanan Gereja Terhadap Anak Belum Maksimal," Website PGI, September 25, 2018, diakses 11 April 2020, https://pgi.or.id/pelayanan-gerejaterhadap-anak-belum-maksimal/. Pdt. Justitia Vox Dei Hattu dalam diskusi Peran dan Panggilan Gereja untuk Kesejahteraan Anak di Grha Oikoumene Jakarta mengatakan bahwa masih banyak gereja yang belum maksimal menyambut panggilannya untuk melayani anak-anak, bahkan pengakuan gereja terhadap anakanak pun belum sepenuhnya terjadi, sebaliknya pelayanan gereja sampai saat ini lebih banyak berorientasi untuk membangun kehidupan beriman warga jemaat dewasa. 
hidup mereka salah dan harus diubah, hanya saja itu berbeda dengan orang dewasa yang cara pandang dunianya lebih dipengaruhi oleh modernisme. Mereka adalah generasi yang disebut oleh Ivy Beckwith dengan generasi "adaptive"3 atau generasi Z dan generasi setelahnya yaitu generasi Alpha yang lahir mulai tahun $2010 .^{4}$

Gereja, khususnya para pelayan anak perlu memahami cara berpikir generasi ini dan mengevaluasi apakah cara-cara dalam melakukan pelayanan anak selama ini sudah tepat, sehingga pelayanan kepada anak dalam konteks kekinian akan menjadi lebih efektif. Dengan memahami bahwa anak-anak yang dilayani oleh gereja saat ini bertumbuh dalam budaya pascamodernisme dan pola pikirnya mencerminkan prinsip-prinsip pascamodernisme, makalah ini akan mengeksplorasi bagaimana pemahaman terhadap worldview anak-anak tersebut perlu diaplikasikan dalam rekonstruksi pelayanan anak di gereja agar menjadi lebih efektif untuk membina kerohanian anak dalam

3. Ivy Beckwith, Postmodern Children's Ministry: Ministry to Children in the 21st Century Church (El Cajon: Zondervan, 2004), 34.

4. Mark McCrindle, "The $A B C$ of XYZ: Understanding the Global Generations," Download (257 Pages | Free)," diakses 8 Juni 2021, http://www.pdfdrive.com/the-abc-of-xyz-understanding-the-global-generationsd175253555.html, p. xiii. Adapun karakateristik dari generasi Alpha masih belum dapat diprediksi secara tepat mengingat usia mereka yang masih muda. Namun gambaran dunia pascamodern akan memberikan penjelasan kepada kita tantangan yang dihadapi oleh generasi $Z$ dan generasi setelahnya, mereka yang dilayani dalam pelayanan anak di gereja. Oleh sebab itu, dalam artikel ini penyebutan generasi $Z$ mewakili generasi $Z$ itu sendiri dan generasi setelahnya yang usianya masih sangat muda untuk menunjukkan karakteristiknya sendiri. Yang jelas, generasi Alpha merupakan peralihan dari generasi $Z$ yang dengan perkembangan teknologi yang semakin pesat, membuat mereka sangat bergantung pada teknologi, gadget, dan aktivitas di media sosial lebih dari pada generasi sebelumnya. 
konteks kekinian. Adapun langkah-langkah yang akan dilakukan adalah: pertama, mengidentifikasi karakteristik Generasi Z dan worldview mereka di bawah pengaruh pascamodernisme; kedua, menganalisa respons para pelayan anak terhadap urgensi rekonstruksi pelayanan anak sebagai tindak lanjut dari pemahaman akan karateristik dan worldview anak-anak yang dilayani saat ini; ketiga, mengajukan usulanusulan dalam melakukan pelayanan anak dalam aspek ibadah, pemberitaan firman, dan peran orangtua dalam formasi spiritual anak.

\section{Generasi Z (Adaptive Generation) dalam Budaya Pascamodern}

Secara bertahap, zaman ini mengalami perubahan dan bergerak kepada paradigma baru yaitu pascamodernisme. Stanley J. Grenz menjelaskan bahwa inti dari apa yang dimaksud dengan pascamodern itu adalah berupa pemikiran dan sikap penolakan terhadap pola pikir modern. ${ }^{5}$ Para pakar sependapat bahwa istilah "pascamodernisme" mulai dikenal pada tahun 1930 -an, di mana awalnya istilah ini dipakai untuk menunjukkan beberapa perkembangan dalam bidang seni. Namun demikian, pencetus istilah "pascamodern" sering dikaitkan dengan seorang yang bernama Arnold Toynbee yang dalam bukunya Study of History menyatakan bahwa era pascamodern sudah dimulai sejak Perang Dunia I berlangsung yang ditandai dengan runtuhnya dominasi Barat dan merosotnya individualisme, kapitalisme, serta Kekristenan, di mana kekuasaan berpindah dari kebudayaan Barat 1996), 13.

5. Stanley J. Grenz, A Primer on Postmodernism (Grand Rapids: Eerdmans, 
kepada kebudayaan non-Barat sehingga muncullah sebuah dunia pluralis baru yang bergeser ke arah irasionalitas. ${ }^{6}$

Sebuah penelitian menunjukkan 30\% Baby Boomers, 50\% Baby Busters dan $60 \%$ generasi milenial memiliki kepekaan pascamodernisme. ${ }^{7}$ Artinya, orang-orang yang memiliki kecenderungan terkuat menuju pandangan dunia pascamodern adalah mereka yang saat ini dilabeli dengan generasi $Y$ atau generasi milenial. Persentase ini mungkin akan lebih besar untuk generasi berikutnya yaitu Generasi Z atau Adaptive Generation. ${ }^{8}$ Beckwith menyebutkan bahwa apa yang kita ketahui tentang generasi $\mathrm{Z}$ masih bersifat spekulatif karena mereka masih terlalu muda untuk menunjukkan karakteristik kelompok manapun. ${ }^{9}$ Namun, karakteristik generasi milenial akan memberikan kepada kita gambaran tentang dunia seperti apa yang ditinggali oleh generasi Z. Adapun karakteristik generasi milenial adalah sebagai berikut: ${ }^{10}$

\begin{tabular}{|l|l|l|}
\hline No. & Karakteristik & \multicolumn{1}{c|}{ Penjelasan } \\
\hline 1 & $\begin{array}{l}\text { Generasi yang } \\
\text { paling dilindungi } \\
\text { dan diinginkan }\end{array}$ & $\begin{array}{l}\text { Kebanyakan dari anak-anak ini adalah hasil dari } \\
\text { kehamilan yang direncanakan. Anak yang } \\
\text { kehadirannya di tengah-tengah keluarga sangat } \\
\text { dinantikan. Mereka diawasi, bertumbuh besar di } \\
\text { kursi mobil dan sabuk pengaman, menggunakan } \\
\text { helm saat bersepeda, bahkan hidup di lingkungan }\end{array}$ \\
\hline
\end{tabular}

6. Grenz, A Primer on Postmodernism, 31.

7. Beckwith, Postmodern Children's Ministry, 21.

8. Generasi milenial digambarkan sebagai anak-anak yang lahir di antara tahun 1980 atau 1982 (ilmu sosial tidak mengklaim sebagai ilmu pasti) dan 2001. Beberapa generational specialist percaya bahwa generasi milenial berakhir pada 11 September 2001 (Beckwith, Postmodern Children's Ministry, 21-22.)

9. Beckwith, Postmodern Children's Ministry, 34.

10. Beckwith, Postmodern Children's Ministry, 29-34. 


\begin{tabular}{|c|c|c|}
\hline & & $\begin{array}{l}\text { yang dikelilingi CCTV untuk memastikan mereka } \\
\text { tetap aman. }\end{array}$ \\
\hline 2 & $\begin{array}{l}\text { Literasi cyber dan } \\
\text { ketergantungan } \\
\text { teknologi }\end{array}$ & $\begin{array}{l}\text { Mereka akrab dengan komputer dan gawai } \\
\text { berteknologi tinggi sejak masih kecil. Globalisasi } \\
\text { membuat mereka dapat terhubung dengan } \\
\text { mudah dengan dunia luas. Mereka adalah } \\
\text { generasi supermultitaskers yang akan bergerak } \\
\text { cepat kepada stimulan yang baru ketika mereka } \\
\text { merasakan bosan. }\end{array}$ \\
\hline 3 & $\begin{array}{l}\text { Sangat toleran } \\
\text { terhadap } \\
\text { perbedaan } \\
\text { pendapat, } \\
\text { budaya, dan gaya } \\
\text { hidup }\end{array}$ & $\begin{array}{l}\text { Generasi ini memiliki keterbukaan emosional dan } \\
\text { intelektual, sangat menghargai kebebasan } \\
\text { pribadi dalam memilih. Mereka yakin secara } \\
\text { intuitif bahwa setiap orang harus melakukan apa } \\
\text { yang benar baginya, setiap orang harus } \\
\text { menemukan kebenarannya sendiri, kisahnya } \\
\text { dalam dunia ini dan menghidupinya dengan } \\
\text { integritas. }\end{array}$ \\
\hline 4 & $\begin{array}{l}\text { Berorientasi pada } \\
\text { pengalaman }\end{array}$ & $\begin{array}{l}\text { Mereka menemukan makna dan nilai dalam } \\
\text { kedekatan dan hidup dalam saat ini. Mereka } \\
\text { ingin mengalami sesuatu sebelum belajar. } \\
\text { Mereka ingin menggunakan semua indera } \\
\text { mereka saat belajar, dan mereka ingin lingkungan } \\
\text { belajar mereka memberikan pengalaman, bukan } \\
\text { hanya fakta atau formula; hal ini dikarenakan } \\
\text { mereka bertumbuh dalam dunia hiburan yang } \\
\text { mensimulasikan setiap pengalaman dengan } \\
\text { teknologi virtual yang memuat fantasi yang tidak } \\
\text { akan dapat mereka akses di kehidupan nyata. }\end{array}$ \\
\hline 5 & $\begin{array}{l}\text { Tidak secara } \\
\text { otomatis } \\
\text { memberikan rasa } \\
\text { hormat mereka } \\
\text { kepada orang } \\
\text { yang lebih tua } \\
\text { atau yang } \\
\text { berotoritas }\end{array}$ & $\begin{array}{l}\text { Oleh karena anak-anak ini cenderung } \\
\text { memercayai dirinya sendiri dan pendapat serta } \\
\text { kebenaran mereka sendiri, mereka tidak } \\
\text { menaruh banyak perhatian pada arahan figur } \\
\text { otoritas. Orang dewasa perlu memenangkan rasa } \\
\text { hormat mereka dengan menjadi apa adanya dan } \\
\text { jujur untuk dapat didengarkan oleh generasi ini. } \\
\text { Mereka menghargai pribadi yang otentik dan apa } \\
\text { adanya. }\end{array}$ \\
\hline 6 & $\begin{array}{l}\text { Generasi yang } \\
\text { memiliki } \\
\text { wawasan } \\
\text { kewarganegaraan }\end{array}$ & $\begin{array}{l}\text { Mereka memiliki keinginan untuk menjadikan } \\
\text { dunia ini lebih baik. Mereka ingin melakukan } \\
\text { sesuatu yang dapat memberikan perbedaan bagi } \\
\text { bangsanya. Mereka adalah generasi yang }\end{array}$ \\
\hline
\end{tabular}




\begin{tabular}{|l|l|l|}
\hline & & $\begin{array}{l}\text { memiliki potensi untuk menjalani kehidupan } \\
\text { yang tidak mementingkan diri sendiri. }\end{array}$ \\
\hline 7 & Generasi rohani & $\begin{array}{l}\text { Mereka terbuka pada ide tentang Allah. Namun, } \\
\text { mereka tidak yakin bahwa ada satu kelompok } \\
\text { atau agama yang memiliki kebenaran mutlak. } \\
\text { Mereka mencari spiritualitas atau iman yang } \\
\end{array}$ \\
& $\begin{array}{l}\text { otentik, yang mencerminkan kisah dan } \\
\text { pengalaman mereka, dan yang bekerja untuk } \\
\text { kehidupan mereka. }\end{array}$ \\
\hline
\end{tabular}

Dibandingkan generasi milenial, generasi Z lahir dan bertumbuh dalam dunia yang jauh lebih terbuka dan semakin tidak aman. Banyak kasus kekerasan pada anak dan tindak penculikan anak yang meresahkan orang tua. Orang tua dari generasi Z bisa jadi jauh lebih protektif daripada orang tua generasi milenial. ${ }^{11}$ Mereka berusaha menyediakan dunia yang aman untuk anak-anak mereka di tengahtengah dunia yang semakin tidak aman. Hal ini dapat memiliki efek luar biasa pada kemampuan generasi ini untuk memercayai orang lain dan diri mereka sendiri. Di samping itu, dibanding generasi milenial maka generasi $Z$ jauh lebih cepat paham teknologi, dan dengan demikian jauh lebih tergantung pada teknologi dibanding generasi sebelumnya. Mereka juga lahir dalam dunia di mana media telah mengaburkan batas antara realita dan fiksi, kebenaran dan ketidakbenaran. Generasi $Z$ akan selalu mempertanyakan apa yang nyata dan tidak nyata, dan mempertanyakan natur kebenaran yang diyakini oleh orang dewasa di bawah paradigma modernisme. ${ }^{12}$

11. Beckwith, Postmodern Children's Ministry, 35.

12. Beckwith, Postmodern Children's Ministry, 37. 
Setiap generasi yang dilayani oleh gereja tentu memiliki tantangannya sendiri. Namun, jika disikapi dengan tepat, tantangan budaya justru dapat menjadi peluang untuk menjangkau generasi ini, baik di dalam maupun di luar gereja. Berdasarkan pemaparan di atas, maka beberapa tantangan yang sekaligus dapat menjadi peluang bagi pelayanan kepada generasi Z antara lain:

i. Adanya pemusatan pada teknologi dan media. Generasi Z dikenal juga sebagai generasi digital yang lahir di era digital dan fasih dalam penggunaan teknologi dan media. Ini menjadi tantangan sekaligus peluang dalam membina generasi ini untuk menggunakan media digital secara positif. Brad Huddleston mengatakan:

I believe God is telling us that technology is permissible, but not every aspect of technology is helpful. As long as technology is used in moderation and as a positive tool, it is good. When technology is missused, or when it is used to excess and it gains power over us, we've crossed the line into addiction and possibly idolatry. ${ }^{13}$

Digital teknologi dapat bermanfaat atau sebaliknya merusak tergantung pada bagaimana kita memanfaatkannya.

ii. Munculnya moralitas baru yang menggeser nilai kebenaran absolut. Jika orang dewasa (di bawah paham modernisme) percaya ada kebenaran absolut dan realitas objektif yang bisa dilihat dan dapat diketahui, generasi pascamodern percaya bahwa realitas dan kebenaran selalu bersifat subjektif. Realitas atau kebenaran bagi

13. Brad Huddleston, Digital Cocaine - A Journey Toward iBalance (Vereeniging: Christian Art Publishers, 2016), 218. 
seseorang bertumbuh dari perspektif dan pengalaman hidup orang tersebut, bukan dipaksakan dari luar. ${ }^{14}$ Beckwith menyebutkan demikian:

[This generation] seem to believe intuitively that each person should do what is right for him; that each person should discover his own truth, his own story of the world, and live that out with integrity. This tolerance of other views and values is classically postmodern ... they value highly personal freedom of choice. ${ }^{15}$

Oleh sebab itu, ide modernisme tentang kebenaran absolut dipandang dengan penuh keraguan oleh generasi pascamodern. Penolakan kepada kebenaran absolut ini tentu menjadi tantangan bagi iman Kristen tetapi juga dapat menjadi peluang ketika pelayan anak dapat mengembangkan cara-cara inovatif untuk membantu anak-anak memikirkan kebenaran dan nilainilai pribadi mereka sendiri.

iii. Penekanan pada pengalaman dan bukan hanya fakta. Generasi pascamodern terbuka dengan ide tentang Allah. ${ }^{16}$ Akan tetapi

14. Pembahasan mengenai kebenaran absolut dan metanarasi dapat dibaca lebih lanjut dalam penjelasan R. Scott Smith, Truth and the New Kind of Christian: The Emerging Effects of Postmodernism in the Church (Wheaton: Crossway, 2005), 143-55, 171-90; Stanley J. Grenz, "Participating in What Frees: The Concept of Truth in the Postmodern Context," Review \& Expositor 100, fall (2003): 688, diakses 1 Maret 2020, http://search.ebscohost.com/login.aspx?direct= true \&db=a6h\&AN=ATLA0000736523\& site=ehost-live.; John S. Feinberg, Can You Believe It's True?: Christian Apologetics in a Modern and Postmodern Era, 1 edition. (Wheaton: Crossway, 2013).

15. Beckwith, Postmodern Children's Ministry, 30.

16. John S. Feinberg menyebutkan: "Since there is no longer a requirement that there must be sufficient evidence to warrant belief in anything, and since there 
mereka ingin mengalami Allah, bukan sekadar belajar tentang Allah atau tahu tentang Allah. Robert Webber berkata: "What appeals to this new generation is the cathedral and the stainedglass window. Take the pews out, let them sit on the floor, burn incense, have Scripture reading, lots of music, chants even, and have communion, and they say, 'Wow, this is me."'17 Mereka ingin mengalami sesuatu sebelum belajar. Mereka ingin menggunakan semua indera mereka saat belajar, dan mereka ingin lingkungan belajar mereka memberikan pengalaman, bukan hanya fakta atau formula. Di mana mereka belajar melalui pengalaman tentang Allah dan iman Kristen? Dalam komunitas Kristen, di mana orang dewasa menunjukkan seperti apa hidup beriman yang benar, seperti apa ibadah dan penyembahan yang benar kepada Allah, dan bukannya sekadar mengajarkan pelajaranpelajaran moral kekristenan kepada generasi ini.

iv. Penolakan pada otoritas atau figur otoritatif dan apresiasi pada pribadi yang real, otentik dan dapat dipercaya. Generasi ini cenderung memercayai diri mereka sendiri dan pendapat serta kebenaran mereka sendiri sehingga mereka tidak menaruh banyak perhatian pada arahan dari orang dewasa atau figur

is no absolute knowledge but rather a plethora of views from varying perspectives, who is to say that there is no God? Some [postmodern people] have found such an idea useful and so they have believed." Menurutnya, skeptisisme pascamodern tidak membuat orang pascamodern menjadi lebih sulit untuk percaya kepada Tuhan daripada orang modern (Feinberg, Can You Believe It's True?, 16.)

17. Sebagaimana dikutip oleh Beckwith, Postmodern Children's Ministry, 31. 
otoritatif lainnya. Namun jika seseorang memenangkan rasa hormat mereka dengan menjadi real dan jujur, mereka akan mendengarkannya. Generasi ini menginginkan orang dewasa bersikap otentik, apa adanya terhadap mereka tanpa berusaha jaim (jaga image) dengan membangun reputasi yang palsu. Dalam majalah Kidscreen, seorang anak perempuan berusia 12 tahun berkata: “Goody-goody characters are very boring. I like watching characters like Bart Simpson because it's funny when they get into trouble and then get themselves out of it. They are more real." ${ }^{\prime 18}$

Apa yang seharusnya dilakukan oleh para pelayan anak dalam menyikapi tantangan-tantangan yang telah dipaparkan di atas? Menurut penulis, kita perlu memiliki kepekaan terhadap pengaruh pascamodernisme pada worldview generasi yang kita layani dengan melakukan kontekstualisasi yang tepat lewat cara-cara yang kreatif dalam melakukan pelayanan kepada anak-anak di era pascamodern ini. Para pelayan anak perlu memikirkan kembali metode yang telah dipakai selama ini dalam pelayanan anak, apa saja yang perlu dipertahankan dan diubah untuk dapat melayani generasi ini dengan efektif.

\section{Generasi Z (Adaptive Generation) dan Pelayanan Anak di Gereja}

Budaya terus berubah dan ada banyak perdebatan tentang sejauh mana gereja harus mengubah metodologi pelayanan anak mereka untuk menjangkau generasi anak saat ini baik yang ada di dalam

18. Dikutip dari Beckwith, Postmodern Children's Ministry, 32. 
maupun di luar gereja. Christopher Lowell Harding, mahasiswa pascasarjana di The Southern Baptist Theological Seminary melakukan sebuah penelitian tentang relevansi budaya dalam pelayanan anak. Dalam disertasinya, Harding menyimpulkan bahwa ada kebutuhan yang diakui untuk perbaikan dalam metodologi pelayanan anak dalam kaitannya dengan relevansi budaya. ${ }^{19}$ Setelah memeriksa informasi yang dikumpulkan melalui wawancara ekstensif dengan para pemimpin dalam pelayanan anak, Harding menulis dalam kesimpulan akhir disertasinya: "The general attitude towards cultural relevancy was very positive. Some of the contributors expressed either a need for increased application of culturally relevant methodology, or in contrast, to be more balanced biblically in relation to culturally relevant methods." 20

Jika di Amerika respons terhadap relevansi budaya dalam pelayanan anak sangat positif, bagaimana dengan konteks pelayanan anak di Indonesia? Penulis melakukan wawancara kepada delapan orang pembina pelayanan anak untuk menganalisa respons mereka terhadap urgensi rekonstruksi pelayanan anak sebagai bentuk aplikasi relevansi budaya saat ini. Adapun narasumber yang diwawancarai terdiri dari tiga pria dan lima wanita yang berdomisili di Jakarta, Bandung, Solo,

19. Christopher Lowell Harding, "Attitudes And Assumptions Of Children's Ministry Experts Concerning Cultural Relevancy" (Disertasi Ed.D, The Southern Baptist Theological Seminary, 2008), 158.

20. Harding, "Attitudes And Assumptions Of Children's Ministry Experts Concerning Cultural Relevancy," 158. 
Surabaya, Kediri, Medan, dan Pontianak. Pertanyaan yang diajukan adalah sebagai berikut: ${ }^{21}$

1. Bagaimana pendapat saudara terhadap pentingnya relevansi budaya dalam pelayanan anak? Apakah relevansi budaya menjadi faktor penentu dalam metodologi pelayanan anak di gereja saudara?

2. Apakah menurut saudara pelayanan anak yang dilakukan saat ini sudah efektif dalam menjangkau dan memuridkan generasi $Z$ yang dipengaruhi pascamodernisme? Perlukah melakukan rekonstruksi dalam pelayanan anak dalam merespons tantangan-tantangan dari budaya pascamodern yang membentuk worldview anak-anak yang dilayani di gereja saudara?

3. Dari evaluasi pribadi saudara terhadap pelayanan anak di gereja saudara, metode pelayanan klasik manakah yang dirasa tidak efektif karena kurangnya relevansi budaya untuk budaya pascamodern? Dan metode pelayanan apa yang perlu tetap dipertahankan karena dirasa tetap efektif?

Secara umum, para pembina pelayanan anak yang diwawancarai memberikan respons yang positif terhadap pentingnya relevansi budaya dalam pelayanan anak. Menurut mereka, penting sekali untuk memahami konteks budaya anak saat ini, karena semakin

21. Pertanyaan-pertanyaan ini diadopsi dari sebagian pertanyaan dalam penelitian Harding, "Attitudes And Assumptions Of Children's Ministry Experts Concerning Cultural Relevancy," 5-6. 
relevan pendekatan pelayanan kita maka semakin besar pula pengaruh yang bisa kita berikan. Sebaliknya semakin kita mengabaikan perubahan budaya, maka semakin kita kehilangan pengaruh terhadap generasi ini. Namun jawaban menjadi bervariasi ketika pertanyaan: apakah relevansi budaya menjadi faktor penentu dalam metodologi pelayanan anak di gereja dan perlukah dilakukan rekonstruksi dalam pelayanan anak untuk merespons tantangan-tantangan dari budaya pascamodern. Para pembina dari generasi yang lebih tua dan pembina yang tinggal di kota kecil cenderung melihat relevansi budaya masih belum menjadi faktor penentu dalam metodologi pelayanan di gereja mereka karena berbagai alasan. Di samping kurangnya fasilitas yang memadai, kualitas sumber daya manusia juga masih jauh di bawah standard. Maka dari itu, rekonstruksi pelayanan dirasa belum terlalu dibutuhkan saat ini, meskipun mereka menginginkan perubahan-perubahan terjadi dalam pelayanan anak di gereja mereka yang dirasa masih belum efektif.

Respons yang berbeda ditunjukkan oleh para pembina dari generasi yang lebih muda dan tinggal di kota besar. Menurut mereka, relevansi budaya menjadi salah satu pertimbangan utama dalam menentukan metodologi pelayanan di gereja mereka. Oleh sebab itu, rekonstruksi pelayanan anak dalam merespons tantangan budaya di rasa sangat perlu untuk dilakukan, meskipun tidak secara total melainkan bertahap dan dalam proses yang panjang. Langkah awal yang dirasa perlu untuk dilakukan dalam usaha ini adalah mengubah paradigma guru dan memperkenalkan pengaruh budaya dalam 
membentuk worldview generasi Z yang dilayani saat ini dalam pelayanan anak.

\section{Bagaimana Seharusnya Gereja Melakukan Pelayanan Anak Dalam Konteks Kekinian?}

Konteks kita yang konkret saat ini adalah kenyataan bahwa anakanak masih merupakan kelompok usia yang terabaikan dalam kebijakankebijakan oleh berbagai pihak, termasuk gereja sebagai komunitas iman. Sebagaimana yang disebutkan Daniel Numahara, "Memang tidak ada pernyataan yang merendahkan atau mengabaikan anak, namun ketika dikaji kebijakan-kebijakannya [Gereja] maka anak dimarginalkan, tidak menjadi prioritas."22 Pentingnya anak-anak dan kesejahteraan masa kecil mereka mungkin telah dideskripsikan dengan sangat baik oleh Howard Hendricks ketika dia mengamati, "Tidak ada sumber daya dasar yang lebih penting bagi masa depan umat manusia daripada anakanak." ${ }^{23}$ Gereja perlu dengan serius memikirkan pelayanan anak karena anak-anak adalah masa depan gereja, calon-calon pemimpin gereja. Model pelayanan anak perlu dikaji ulang, apakah sudah efektif dalam menjawab tantangan zaman ini bagi pelayanan kepada generasi $Z$.

Rekonstruksi metodologi pelayanan anak dalam rangka relevansi budaya memang tidak dapat dilakukan secara mendadak dan menyeluruh. Hal ini perlu dilakukan secara bertahap, melalui proses

22. Tim KTAK Anak Bersinar Bangsa Gemilang Jaringan Peduli Anak Bangsa, Teologi Anak: Sebuah Kajian (Jakarta: Literatur Perkantas, 2019), 11.

23. Sebagaimana dikutip oleh Harding, "Attitudes And Assumptions Of Children's Ministry Experts Concerning Cultural Relevancy," 1. 
yang panjang, setelah melakukan evaluasi yang menyeluruh terhadap pelayanan anak saat ini di gereja lokal. Namun dengan memperhatikan tantangan dan peluang dari karakteristik generasi Z, setidaknya ada tiga hal yang perlu dipertimbangkan oleh gereja dalam melakukan pelayanan anak dalam konteks kekinian, yaitu berkaitan dengan aspek ibadah, pemberitaan firman, dan peran orang tua dalam formasi spiritual anak.

\section{Ibadah}

Pada umumnya, ibadah anak terpisah dengan ibadah jemaat dewasa. Anak-anak diarahkan ke acara atau program Sekolah Minggu yang dianggap lebih menyenangkan dan sesuai dengan usia mereka daripada beribadah bersama dengan jemaat dewasa lainnya. Namun, menjadi bagian dari ibadah bersama jemaat sangat penting bagi pembentukan spiritual anak-anak. John Westerhoff menulis bahwa jika kita ingin anak-anak memiliki iman, mereka harus memiliki kesempatan untuk beribadah dengan orang dewasa di gereja. ${ }^{24}$ Ketika anak-anak terlibat dalam ibadah bersama yang bermakna, mereka mengalami potensi positif yang mereka miliki sebagai anak-anak Allah. ${ }^{25}$

24. Sebagaimana dikutip oleh Beckwith, Postmodern Children's Ministry, 142.

25. Beckwith, Postmodern Children's Ministry, 142. Menurutnya, ibadah bukan hanya saat content iman disampaikan, tetapi juga saat ketika gereja mengkomunikasikan perasaan, nuansa halus, dan makna transenden dari iman. Berpartisipasi dengan orang dalam penyembahan kepada Tuhan juga membantu anak-anak mengembangkan rasa memiliki terhadap komunitas. Melalui partisipasi dalam ibadah, seorang anak mengembangkan identitasnya dengan umat Allah dan sebagai pribadi Allah. 
Sebagaimana yang dipaparkan sebelumnya, generasi Z ingin mengalami Allah dan bukan sekadar tahu tentang Allah. Dalam ibadah, anak belajar dan mengalami Allah lewat ibadah bersama dengan orang dewasa lainnya.

Dalam pertumbuhan spiritual anak, peran orang dewasa dari segala usia dalam komunitas Kristen sangat penting. David M. Csinos dan Ivy Beckwith berkata:

[Children's ministry] aims at nurturing the whole life of the child and not compartmentalizing the child's "church life" from the rest of child's life. It realizes that children feel God's love when they are surrounded by a close-knit faith community who loves them and sees them as valued participants. It realizes that children make the values of God's reign their own by seeing them lived out radically in their churches and homes-not simply by learning about them in a classroom or through a programmed activity. It understands that children are learners and teachers, and that they have as much to teach adults about life in God's kingdom as we adults have to teach them. ${ }^{26}$

Anak-anak belajar tentang iman Kristen dalam komunitas lintas generasi, di mana anak belajar satu sama lain, anak yang lebih muda belajar dari remaja dan orang dewasa lain, dan orang dewasa belajar dari anak-anak dan remaja serta dari orang dewasa yang lebih tua, sehingga komunitas ini bertumbuh bersama ke arah Kristus. Anak perlu memiliki sense of belonging, karena setiap orang perlu merasa bahwa dirinya adalah bagian dari komunitas yang sadar diri dan bahwa melalui partisipasi aktifnya dia dapat memberikan kontribusi pada kehidupan

26. David M. Csinos and Ivy Beckwith, Children's Ministry in the Way of Jesus (Downers Grove: IVP Books, 2013), 38. 
ini, dan internalisasi kepercayaan dan kepemilikan ini sangat penting untuk identitas iman. ${ }^{27}$

Pada umumnya, gereja memisahkan anak-anak dari ibadah jemaat karena beberapa alasan: mereka berisik, menyebabkan gangguan, dan mungkin tidak dapat memahami apa yang sedang terjadi dalam ibadah. Caroline Fairless, seorang pemimpin dalam gerakan untuk melibatkan anak dalam ibadah jemaat mengakui kesulitan yang ada dalam meyakinkan orang dewasa tentang pentingnya melibatkan anakanak dalam ibadah umum. ${ }^{28}$ Menurutnya, memasukkan anak-anak ke dalam ibadah bersama memang berlawanan dengan kebiasaan dan dapat meresahkan, tetapi gereja yang benar-benar tertarik dengan formasi spiritual anak perlu bergumul dengan serius tentang pentingnya hal ini. ${ }^{29}$

Persiapan praktis yang bisa dilakukan oleh gereja adalah dengan memberikan pengertian kepada jemaat melalui khotbah tentang pentingnya seluruh komunitas iman (baik anak maupun jemaat dewasa) untuk beribadah bersama sebagai tindakan pembentukan spiritual, dan juga mempersiapkan anak-anak dengan memberikan pemahaman yang cukup tentang makna liturgi ibadah sehingga mereka bisa mengikuti seluruh ibadah dengan baik. Penggunaan teknologi dan media yang lebih intens dalam ibadah bersama akan sangat menolong agar anak-

27. Shirley K. Morgenthaler, Jeffrey B. Keiser, and Mimi L. Larson, "Nurturing The Infant Soul: The Importance of Community And Memories In The Spiritual Formation of Young Children," Christian Education Journal 3 (Fall 2014): 248.

28. Dikutip dari Beckwith, Postmodern Children's Ministry, 145.

29. Beckwith, Postmodern Children's Ministry, 145. 
anak lebih paham dan dapat berkonsentrasi. Bagaimanapun, ketika gereja dapat memahami prinsip yang disebutkan oleh Robert J. Keeley: "Children should be a part of congregational worship and they should also have opportunities to experience developmentally appropriate worship," ${ }^{30}$ maka usaha untuk melibatkan anak-anak dalam ibadah bersama kepada Allah, sebagai salah satu bentuk pengasuhan anak-anak dalam iman mereka, patut untuk diperjuangkan.

\section{Pemberitaan Firman}

Dalam pascamodernisme, kebenaran terhubung dengan narasi. ${ }^{31}$ Grenz menyebutkan: "Postmodernism... see an integral connection between story and truth. Truth is lived narrative. And the goal of storytelling is not simply to extract the truth that it supposedly illustrates, but to 'inhabit' the story.'"'32 Bagi kaum pascamodern, kebenaran cerita tidak terletak pada prinsip-prinsip yang diwujudkannya, tetapi pada kisah itu sendiri. Kebenaran muncul ketika para pendengar tertarik ke dalam narasi, di mana mereka menjadi salah satu tokoh dalam narasi tersebut dan menemukan kebenaran itu bagi dirinya. Worldview demikianlah yang dimiliki oleh generasi Z dalam pelayanan anak.

30. Robert J. Keeley, Helping Our Children Grow in Faith: How The Church Can Nurture The Spiritual Development Of Kids (Grand Rapids: Baker Books, 2008), 97.

31 Grenz, "Participating in What Frees: The Concept of Truth in the Postmodern Context," 690.

32 Grenz, "Participating in What Frees: The Concept of Truth in the Postmodern Context," 691. 
Pada umumnya guru Sekolah Minggu mengajar anak-anak generasi $Z$ dengan pendekatan modernisme. Orang modern tertarik untuk menjawab pertanyaan seperti: kebenaran universal apa yang ingin Yesus sampaikan kepada murid-murid-Nya? Atau poin apa yang ingin disampaikan oleh Yohanes dari kisah Lazarus? Namun pendekatan ini sulit diterima oleh anak-anak. Generasi Z ingin mengetahui apa yang dikatakan Alkitab dan kemudian memutuskan sendiri apa yang ingin mereka lakukan dengannya; dengan kata lain mereka menginginkan sistem studi Alkitab yang terbuka, bukan yang tertutup. ${ }^{33}$ Oleh sebab itu, ketika kita membagikan kisah Alkitab kepada anak-anak generasi Z, kita perlu membiarkan kisah itu berdiri sendiri. Yang guru harus lakukan adalah memberi tahu anak-anak kisah-kisah Alkitab, mengizinkan mereka untuk mengalami kisah tersebut dan membantu mereka masuk ke dalam cerita Alkitab. Peran guru tidak lagi sebagai orang yang memberi anak aplikasi kehidupan dari cerita Alkitab tersebut, tetapi pendamping yang mengizinkan imajinasi anak bekerja dalam cerita itu dan membiarkan cerita itu berbicara kepada mereka dalam konteks khusus mereka sendiri. Guru harus mengembangkan cara-cara inovatif untuk membantu anak-anak memikirkan kebenaran dan nilai-nilai pribadi mereka sendiri dari kisah-kisah Alkitab.

Beckwith memberikan beberapa konsep atau cara yang dapat dipakai untuk membantu anak-anak mengeksplorasi dan mengalami teks kuno dan kisah-kisah Alkitab: ${ }^{34}$ pertama, mengembangkan learning 
experience design di mana anak diajak untuk mengeksplorasi kehidupan di zaman Alkitab yang memungkinkan mereka mengalami kisah itu sendiri; kedua, melakukan praktik spiritual kuno, yaitu Lectio Divina dan Examen; ${ }^{35}$ ketiga, menerapkan Godly Play, yaitu metode penemuan yang melibatkan seluruh diri anak baik fisik, hati, pikiran, indera, intuisi, dan mengajarkan kebergantungan kepada gracious God yang nyata dan dapat diakses dalam semua misteri kehidupan, baik yang sedih maupun penuh sukacita. Memang tidak ada satu pun cara yang sangat mudah untuk memperkenalkan firman Allah yang hidup itu kepada anak-anak, tetapi konsep atau cara di atas dapat menolong untuk memberikan fondasi bagi pengajaran Alkitab secara unik dalam konteks gereja masing-masing.

35. Lectio Divina adalah salah satu praktik spiritual kuno gereja yang dapat digambarkan sebagai pembacaan spiritual dari teks-teks tulisan suci di mana seseorang mendengarkan dengan sepenuh hati tentang apa yang Tuhan katakan melalui cerita itu. Ini adalah tindakan merefleksikan teks Alkitab untuk berhubungan dengan Allah. Sederhananya (dan tidak ada aturan yang ditetapkan untuk Lectio Divina), seseorang membaca teks perlahan beberapa kali, memungkinkan kata-kata dan frasa masuk ke dalam pikiran seseorang. Terkadang sebuah kata atau frasa melompat keluar dari cerita, atau sebuah pemikiran muncul, dan seseorang harus meluangkan waktu untuk menanggapi kata-kata, frasa, atau pikiran itu. Akhirnya, Lectio Divina adalah istirahat dalam Firman Tuhan ketika kita mendengarkan Tuhan berbicara kepada kita di tingkat terdalam dari keberadaan kita. Sedangkan Examen adalah praktik yang dilakukan pada akhir hari ketika para peserta berbicara bersama tentang hal-hal yang terjadi pada siang hari yang melemahkan semangat dan energi mereka, yang juga dikenal sebagai kehancuran. Kemudian mereka berbicara tentang hal-hal yang terjadi pada siang hari yang mendorong mereka atau memberi mereka energi, juga dikenal sebagai penghiburan. Pada akhir waktu kita berbicara kepada Tuhan tentang semua hal ini, membawa Tuhan ke pusat peristiwa penting dalam hidup kita (lih. Beckwith, Postmodern Children's Ministry, 135-36.) 


\section{Peran Keluarga dalam Formasi Spiritual Anak}

Jika kita menelusuri Alkitab, kita akan mendapati bahwa Allah memberikan gagasan-Nya tentang struktur keluarga dan peran keluarga dalam pembentukan spiritual generasi berikutnya (1Kor. 7; Mzm. 139; Ul. 6; Kej. 2; Ef. 5; Mal. 2; Mrk. 10; Mzm. 78). ${ }^{36}$ Peran keluarga adalah untuk menyediakan pengasuhan dan pelatihan rohani, untuk menginjili, memuridkan, dan membesarkan anak-anak yang saleh. Namun, kita ada di dunia yang sudah jatuh di mana kehidupan keluarga telah menjadi rusak. Di situlah peran gereja untuk mendukung dan membantu orang tua/keluarga dalam proses ini, dan berperan menyediakan tempat pengembangan spiritual bagi anak-anak ketika tidak berada di rumah. Jadi gereja bukan mengambil alih tugas dan peran orang tua/keluarga melainkan memperlengkapi orang tua dalam tugas dan peran pembentukan spiritual anak-anaknya. Seperti yang ditekankan Catherine Stonehouse dan Scottie May:

The church and the family must partner together for the effective nurture and Christian formation of their children. Neither will be as successful alone. This partnership is biblical. Expecting the nuclear family to do the work of faith formation on its own is foreign to the principles of Scripture. ${ }^{37}$

36. Michelle D. Anthony, "Children's Ministry in the Context of the Family for Spiritual Formation" in A Theology for Family Ministry, ed. Michael Anthony and Michelle Anthony (Nashville, Tennesse: B\&H Academic, 2011), 207.

37. Catherine Stonehouse and Scottie May, Listening to Children on the Spiritual Journey: Guidance for Those Who Teach and Nurture (Grand Rapids: Baker Academic, 2010), 138. 
Pada umumnya gereja dilihat sebagai gereja bagi orang dewasa saja, sehingga menjadi hal yang umum untuk memisahkan keluarga berdasarkan usia sehingga orang tua dan anak tidak pernah berada dalam satu ruangan yang sama untuk beribadah. Gereja jarang membahas tentang bagaimana memperkuat peran orang tua, atau bahkan keterlibatan orang tua dalam pembentukan spiritual anak. Karena itu, terbentuklah mentalitas dalam diri orang tua untuk sekadar "mengantarkan" anak-anak mereka untuk dibina secara kerohanian dalam pelayanan anak di gereja. Michelle D. Anthony mengatakan:

Although the church and its educator play a significant role in the spiritual endeavors of its children, an alarming number of parents have forgotten, ignored, or are ignorant of what their responsibilities are in the child-rearing process. Parents have strayed far from the biblical ideal for family life, and this gap between what is and what should be makes clear the need for a comprehensive yet empowering family ministry within the church. 38

Gereja perlu mendorong dan memperlengkapi orang tua untuk kembali kepada peran yang Allah rancang bagi mereka untuk berperan aktif dalam pembentukan spiritual anak-anaknya.

Bagaimana dengan anak-anak yang datang ke gereja tanpa keluarga karena mungkin keluarganya bukan orang percaya atau anakanak yang memiliki keluarga disfungsional? Anggota-anggota dari komunitas iman harus berperan sebagai keluarga dan orang tua rohani

38. Anthony, "Children's Ministry in the Context of the Family for Spiritual Formation," 219-20. 
bagi anak-anak ini. ${ }^{39}$ Seorang anak kehilangan banyak hal dalam cara pembinaan rohani yang positif ketika keluarganya disfungsional, dalam krisis, atau orang tuanya acuh tak acuh dengan hal-hal spiritual. Komunitas iman perlu terlibat dalam membantu anak-anak dan keluarga yang disfungsional tersebut. Sebagaimana yang Beckwith tekankan dalam bukunya dan dalam pelayanan anak yang dia lakukan:

Children's ministry... must focus on families as the center of a child's spiritual nurture and formation. The church cannot do right by its children without including families, but families cannot go it alone. Faith communities must partner with families, helping them understand their role in the soul care of their children and supporting them in this task. Only then will we see lasting spiritual growth and understanding in our children. ${ }^{40}$

\section{Kesimpulan}

Zaman telah mengalami perubahan dan sedang bergerak kepada paradigma baru, yaitu pascamodernisme. Berdasarkan penelitian, orang-orang yang memiliki kecenderungan terkuat menuju pandangan dunia pascamodern adalah generasi milenial atau generasi $Y$ dan generasi setelahnya atau generasi $Z$, anak-anak yang saat ini dilayani dalam pelayanan anak (Sekolah Minggu) di gereja. Generasi Z tidak melihat dunia dengan cara yang sama seperti orang dewasa melihatnya. Namun ini tidak berarti bahwa pandangan hidup mereka salah dan harus diubah; hanya saja itu berbeda dengan orang dewasa yang cara pandang dunianya lebih dipengaruhi oleh modernisme. Oleh sebab itu, gereja

39. Beckwith, Postmodern Children's Ministry, 120.

40. Beckwith, Postmodern Children's Ministry, 121. 
dan para pelayan anak perlu memahami cara berpikir generasi $Z$ ini dan mengaplikasikannya dalam metodologi pelayanan anak di gereja.

Beberapa tantangan yang sekaligus dapat menjadi peluang bagi pelayanan kepada generasi Z antara lain: adanya pemusatan pada teknologi dan media; munculnya moralitas baru yang menggeser nilai kebenaran absolut; penekanan pada pengalaman dan bukan hanya fakta; dan terakhir, penolakan pada otoritas atau figur otoritatif dan apresiasi pada pribadi yang real, otentik dan dapat dipercaya. Menghadapi tantangan yang demikian, para pelayan anak perlu memiliki kepekaan terhadap pengaruh pascamodernisme pada worldview generasi yang kita layani dengan melakukan kontekstualisasi yang tepat lewat cara-cara yang kreatif dalam melakukan pelayanan kepada anak-anak di era pascamodern ini.

Ada tiga hal yang perlu dipertimbangkan oleh gereja dalam melakukan pelayanan anak dalam konteks kekinian yaitu: pertama, melibatkan anak-anak dalam ibadah bersama dengan jemaat dewasa sebagai salah satu bentuk pengasuhan anak-anak dalam iman mereka, di mana dalam ibadah tersebut anak belajar dan mengalami Allah (bukan sekadar tahu tentang Allah) lewat ibadah bersama dengan orang dewasa lainnya. Kedua, dalam hal pemberitaan firman, pelayan anak perlu menerapkan sistem studi Alkitab yang terbuka, bukan yang tertutup, di mana anak dituntun untuk memikirkan dan menemukan kebenaran serta nilai-nilai pribadi mereka sendiri dari kisah-kisah Alkitab. Ketiga, mendorong dan memperlengkapi orang tua untuk 
kembali kepada peran yang Allah rancang bagi para orang tua untuk berperan aktif dalam pembentukan spiritual anak-anaknya.

\section{Daftar Pustaka}

Buku

Anthony, Michelle D. “Children's Ministry in the Context of the Family for Spiritual Formation" in A Theology for Family Ministry. Diedit oleh Michael Anthony and Michelle Anthony. Nashville, Tennesse: B\&H Academic, 2011.

Beckwith, Ivy. Postmodern Children's Ministry: Ministry to Children in the 21st Century Church. El Cajon: Zondervan, 2004.

Csinos, David M. and Ivy Beckwith. Children's Ministry in the Way of Jesus. Downers Grove: IVP Books, 2013.

Feinberg, John S. Can You Believe It's True?: Christian Apologetics in a Modern and Postmodern Era. Wheaton: Crossway, 2013.

Grenz, Stanley J. A Primer on Postmodernism. Later Printing edition. Grand Rapids: Eerdmans, 1996.

Harding, Christopher Lowell. "Attitudes And Assumptions of Children's Ministry Experts Concerning Cultural Relevancy." Disertasi Ed.D., The Southern Baptist Theological Seminary, 2008.

Huddleston, Brad. Digital Cocaine - A Journey Toward iBalance. Vereeniging: Christian Art Publishers, 2016.

Keeley, Robert J. Helping Our Children Grow in Faith: How The Church Can Nurture The Spiritual Development Of Kids. Grand Rapids: Baker Books, 2008.

Smith, R. Scott. Truth and the New Kind of Christian: The Emerging Effects of Postmodernism in the Church. Wheaton: Crossway, 2005.

Stonehouse, Catherine and Scottie May, Listening to Children on the Spiritual Journey: Guidance for Those Who Teach and Nurture. Grand Rapids: Baker Academic, 2010.

Tim KTAK Anak Bersinar Bangsa Gemilang Jaringan Peduli Anak Bangsa. Teologi Anak: Sebuah Kajian. Jakarta: Literatur Perkantas, 2019.

\section{Website}

Grenz, Stanley J. "Participating in What Frees: The Concept of Truth in the Postmodern Context," Review \& Expositor 100, fall (2003): 688. 
Diakses 1 Maret 2020. http://search.ebscohost.com/login.aspx? direct=true \&db=a6h\&N=ATLA0000736523\& site=ehost-live.

Markus. "Pelayanan Gereja Terhadap Anak Belum Maksimal." Website PGI, September 25, 2018. Diakses 11 April 2020. https://pgi.or.id/ pelayanan-gereja-terhadap-anak-belum-maksimal/.

McCrindle, Mark. "The ABC of XYZ: Understanding the Global Generations Download (257 Pages|Free)." Diakses 8 Juni 2021. http://www. pdfdrive.com/the-abc-of-xyz-understanding-the-global-generatio ns-d175253555.html.

Morgenthaler, Shirley K. Jeffrey B. Keiser, and Mimi L. Larson, "Nurturing The Infant Soul: The Importance Of Community And Memories In The Spiritual Formation of Young Children," Christian Education Journal 3 (Fall 2014): 244-258. 